$\Phi=5$

\title{
Determinants of Health Service Utilization Among Users of Dokolo Health Centre IV, Dokolo District: A Community Perspective
}

\author{
Francis Ojok ${ }^{1}$, Samuel Mukasa ${ }^{1}$, Kizito Omona $[\mathrm{PhD}]^{2 *}$ \\ ${ }^{1}$ MPH Students, Uganda Martyrs University, Faculty of Health Sciences, P. O. Box 5498, Kampala, Uganda \\ ${ }^{2 *}$ Lecturer, Uganda Martyrs University, Faculty of Health Sciences, P. O. Box 5498, Kampala, Uganda \\ *Corresponding author E-mail:komona@umu.ac.ug
}

\begin{abstract}
Introduction: Health services utilization (HSU) is an important health outcome indicator, a surrogate measure of access to healthcare that influences the outcomes of health status and consumer satisfaction. Healthcare is central to community well-being as well as a fundamental aspect of life.

Objective: The study sought to assess determinants of health service utilization among users of Dokolo Health Centre IV, Dokolo district. Methods: A cross sectional analytical design, which employed both quantitative and qualitative approaches, was used between January and July, 2020. A total of 396 respondents participated. Data was collected using Semi-structured questionnaires and Focus Group Discussion guide. Analysis was done using SPSS and qualitative data was analyzed verbatim.

Results: Only $26.8 \%$ of the users were satisfied with services provided in the health facility. Living environments of respondents was the only socio-demographic factor that determined HSU $(p=0.046)$. Living in urban area was 1.6 times more likely to be a determinant of HSU than living in rural setting [COR=1.571, 95\% CI (0.986-2.504)]. The study found that being a female was 1.14 times more likely to utilize health services (COR=1.135, 95\% CI (0.741-1.739)). Similarly, majority of the respondents who were peasants, 174(43.9\%), utilized health services from the facility as opposed to their formally employed counterparts. Thus, being formally employed was 0.7 times less likely to utilize health services $(C O R=0.655,95 \%$ CI $(0.29-1.476))$. Satisfaction with services $(p=0.000)$, level of satisfaction $(p=0.000)$ and distance to health facility $(p=0.033)$ were enablers of HSU. Being very satisfied was 16 times more likely for one to utilize health services $[C O R=16,95 \%$ CI (0.000-0.001)]. Most of the respondents rated the quality of care as poor.

Conclusion: Health service utilization remains quite low in many rural health facilities of Uganda.
\end{abstract}

Keywords: Health Service Utilization; Users; Community Perspectives.

\section{Introduction}

\subsection{Background of the study}

Utilization is defined as the outcome of the interaction between health professionals and patients (Donabedian, 1973). However, in economic terms, it corresponds to the production of health services and more specifically to the production of health services by physicians (Folland, Goodman, \& Stano, 2006). Whereas, utilization is a multi-dimensional approach(Donabedian, 1973), this study adopted a patients' perspectives as done in other studies(Haggerty, et al., 2008; Silva, Contandriopoulos, Pineault, \& Tousignant, 2011).

According to the Andersen model, Health services utilization is a function of three components. These are; (1) predisposing factors, which may include demographic characteristics, (2) enabling factors or conditions that make health service resources available to an individual and (3) perceived need factors. The demographic factors include age, gender, occupation and marital status among others. Enabling factors are things like income levels and access to facility. Perceived need factors include quality of care, client satisfaction and others, which are described as the most immediate reason for health services use to take place (Qais, et al., 2017).

Within the global policy arena, there is a welcome focus on quality driven by the recent adoption of the Sustainable Development Goals (SDGs). These SDGs advocate for achievement of universal health coverage (UHC), including financial risk protection, access to quality essential health care services and access to safe, effective, quality, and affordable essential medicines and vaccines for all (Lancet, 2014). While historically UHC has focused on expanding access to services and reducing financial barriers, there is increasing recognition that these services should be of high quality (Gutierrez, Teshome, \& Neilson, 2018). In most developing countries, there is need for increased expenditure on healthcare provision and parameters need to be put in place to ensure its sustainability.

Uganda has a tax-based health system in which health services are provided free at the point of use. However, utilization of health services is affected by a complex set of factors namely predisposing, enabling factors and need factors. The predisposing factors include socio-demographic determinants such as age, sex, socioeconomic status (SES), family status, immigration status, and aspects such as health literacy and health beliefs relating to the person's health self-perceived health status, and the availability of the health care services 
on offer (Terfa \& Germossa, 2019). Enabling factors refer to individual or structural resources enabling or increasing the likelihood of service use. This includes aspects such as income, health insurance coverage, availability of health services or regular sources of care, and means of transportation (Brzoska, Erdsiek, \&Dorothee, 2017; Terfa \& Germossa, 2019) and Need for care factors include poor or ill health, chronic conditions, and limited physical activity performance.Little is known about which demographic, social, behavioural and health-related factors influence utilization of health services in Dokolo district. To develop policy that can address the continued inequality in health care utilization in Dokolo district, the study sought to examine determinants of utilization of health services in the district.

\subsection{Background to the study area}

Dokolo Health Centre IV is a public health facility in Northern Uganda, situated north of Akongodiek and close to Agwencibange Nursery School, in Dokolo district. Dokolo District is bordered by Lira District to the northwest, Alebtong District to the northeast, Kaberamaido District to the east and south, Amolatar District to the southwest, and Apac District to the west. The administrative headquarters of the district are located approximately 60 kilometres $(37 \mathrm{mi})$, by road, southeast of Lira, the largest city in the sub-region. The coordinates of the district are $0155 \mathrm{~N}, 3310 \mathrm{E}$.

\subsection{Problem statement}

Over the past 20 years, Uganda has made great strides in the coverage of health services across the country and significant progress in improving the health of its citizens have been realized but coverage of key indicators remains low nationally ( Musoke \& Boynton, 2018). The northeast region had $77 \%$ of its population attending public health facilities compared to only $17 \%$ in Kampala (Mwesigwa \& Okumu, 2020). It should be noted that while the importance of individual factors and contextual factors in shaping the use of health services has been alluded to in the literature(Guinness, Repon , \& Augu, 2018), increasing observed discrepancy between health service utilizations cannot be explained by only one factor but many.

Poor utilization is caused by poverty, inaccessibility, inappropriate health-promoting practices and negative attitudes, among others. Each of these factors varies in its intensity from area to area in Uganda. However, little research and documentation on the relative importance of such factors has been carried out in Dokolo health centre IV. Therefore, this study represented one of the few studies geared specifically towards understanding determinants of low levels of health care services utilization in Dokolo district.

\subsection{Objectives of the study}

The objectives of the study were as follows;

1) To determine the level of satisfaction of utilization of health services among users Dokolo Health Centre IV, Dokolo district between January, 2020 and July, 2020.

2) To examine the socio-demographic determinants of health service utilization among users of Dokolo Health Centre IV, Dokolo district between January, 2020 and July, 2020.

3) To determine the enabling determinants of health service utilization among users of Dokolo Health Centre IV, Dokolo district between January, 2020 and July, 2020.

4) To establish the opinions of health service users on utilization of health services in Dokolo Health Centre IV, Dokolo district between January, 2020 and July, 2020

\section{Methods}

\subsection{Study design}

The design was descriptive and analytical Cross-sectional study, undertaken before between January, 2020 and July, 2020. It took both qualitative and quantitative dimensions.

\subsection{Study population}

The study populations were community households in Dokolo sub-county or patients at Dokolo Health Centre IV, a public health facility, who reside in that community.

\subsection{Study unit}

The units of study were; a household or a patient who visited Dokolo Health Centre IV within the study period and resides in Dokolo Sub-county.

\subsection{Sample size}

The sample size was calculated using Yamane's formula since the population size was known, level of precision at 5\% and a confidence interval of $95 \%$ (Israel, 1992).The total number of households was 35000households. Thus;

$\boldsymbol{n}=\frac{\mathrm{N}}{\mathbf{1 + N}(e)^{2}}=\frac{35000}{\left[\mathbf{1 + 3 5 0 0 0}\left(0_{\left.\left.0.05^{2}\right)\right]}\right.\right.}=395.480226 \approx 396$ households.

Where "n" was the sample size, "N" was the proportion size and "e" was the level of precision. Therefore, the sample size was 396 households.

\subsection{Sampling techniques}


Simple random sampling technique was used to select households within Dokolo sub-county and again, simple random technique was use to select the participant to interview provided he or she is an adult 18years and above. All participants who met the inclusion criteria were interviewed. This exercise continued by way of picking until the sample size, $n$, was reached.

\subsection{Data collection tools}

The following tools were used; Semi-structured questionnaires and Focus Group Discussion (FGD) guides.

Semi-structured researcher-administered questionnaire was used by the researcher to record individual responses from participants. Three FGDs were held; two in the community and one for patients from the health facility.

\subsection{Data entry, analysis and presentation methods}

The quantitative data generated was entered into Microsoft excel and Statistical Package for Social Sciences (SPSS) software of a computer for analysis. Qualitative data were coded, transcribed and content analysis done. Themes and sub-themes were generated.The results were presented in narrative/descriptive statements, tables and graphs as appropriate.

\subsection{Ethical consideration}

As guided by Centre for Innovation in Research and Teaching ([CIRT], 2018), clearance from the Uganda Martyrs University research faculty was obtained. The names of the respondents were not used for the analysis to conceal their identities for purpose of confidentiality. Informed consent from the respondents was sought.

\section{Results}

\subsection{Background characteristics of respondents}

The socio-demographic characteristics of the respondents were examined by univariate analysis and the results are summarized in table 1 below.

Table 1: Socio-Demographic Characteristics of Respondents

\begin{tabular}{|c|c|c|c|c|c|c|}
\hline \multicolumn{4}{|c|}{ Socio-demographic Variables } & \multirow{2}{*}{$\begin{array}{l}\text { Frequency }(\mathbf{n}=396) \\
109\end{array}$} & \multirow{2}{*}{$\begin{array}{l}\text { Percent (\%) } \\
27.5\end{array}$} & \multirow{2}{*}{$\begin{array}{l}\text { Cumulative \% } \\
27.5\end{array}$} \\
\hline 1. & Age & - & Less than 30years & & & \\
\hline & & & 30-40years & 190 & 48.0 & 75.5 \\
\hline & & - & More than 40years & 97 & 24.5 & 100.0 \\
\hline 2. & & - & Female & 256 & 64.6 & 100.0 \\
\hline \multirow[t]{2}{*}{3.} & Marital status & - & Married & 248 & 62.6 & 62.6 \\
\hline & & - & Not married & 148 & 37.4 & 100.0 \\
\hline 4. & Occupation & - & Peasant & 298 & 75.3 & 75.3 \\
\hline \multirow[t]{4}{*}{5.} & Education & - & No education & 84 & 21.2 & 21.2 \\
\hline & & - & Primary education & 182 & 46.0 & 67.2 \\
\hline & & - & Post-primary education & 58 & 14.6 & 81.8 \\
\hline & & - & Tertiary education & 72 & 18.2 & 100.0 \\
\hline \multirow[t]{3}{*}{6.} & Religion & - & Christians & 300 & 75.8 & 75.8 \\
\hline & & - & Muslims & 67 & 16.9 & 92.7 \\
\hline & & - & Others & 29 & 7.3 & 100.0 \\
\hline 7. & Living environment & - & Rural & 285 & 72.0 & 72.0 \\
\hline
\end{tabular}

There were 396 respondents with a total response rate of $100 \%$. The mean age was 1.97 years with standard deviation (SD) 0.722 . Most of the respondents (48\%) were in the age group 30-40years and majority $(64.6 \%)$ was of female gender. $62.6 \%$ of these respondents were married whereas $75.2 \%$ were peasant leaving only $24.7 \%$ as formerly employed respondents. Most of them had either no education $(21.2 \%)$ or primary education $(46.0 \%)$. Majority of the said respondents were Christians $(75.8 \%)$ and live in rural areas $(72.0 \%)$.

\subsection{Level of satisfaction with utilization of health services among users}

To determine level of satisfaction of respondents with services in the health facility, data was collected of those who got services from the facility and those who were satisfied with the services. Results are shown in table 2 below.

Table 2: Service-Related Characteristics of Respondents

\begin{tabular}{|c|c|c|c|c|}
\hline & & Frequency & Percent & Cumulative \% \\
\hline \multirow{2}{*}{ Respondent got service(s) } & True & 229 & 57.8 & 57.8 \\
\hline & False & 167 & 42.2 & 100.0 \\
\hline \multirow{2}{*}{ Respondent satisfied with Service(s) } & Yes & 106 & $26.8 \%$ & $26.8 \%$ \\
\hline & No & 290 & $73.2 \%$ & $100.0 \%$ \\
\hline
\end{tabular}

The result showed that $57.8 \%$ of the respondent got service(s) from the health facility, whereas only $26.8 \%$ of them were satisfied with services provided in Dokolo health centre IV. Therefore, most of the respondents (73.2\%) were no satisfied with services in the facility. A likert scale, ranging from very dissatisfied to very satisfied, was generated to rate the respondents' level of satisfaction with services in the facility. The results are shown in figure 1 below. 


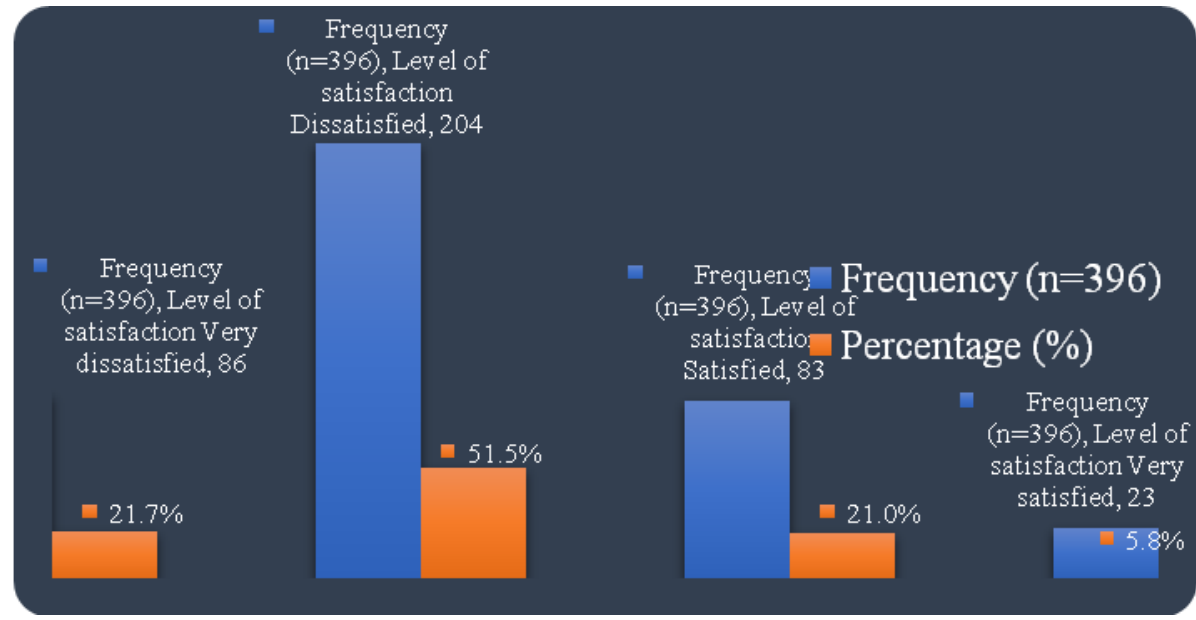

Fig. 1: Likert Scale of Level of Satisfaction with Health

From figure 3 above, $21.7 \%$ of the respondents were very dissatisfied and only $5.8 \%$ of them were very satisfied. Therefore, overall, only $26.8 \%$ of the users were at least satisfied with services provided in the health facility.

\subsection{Socio-demographic determinants of health service utilization}

A cross-tabulation and bivariate analysis was done to determine the socio-demographic determinants of health services utilization. The results are shown in table 3 below.

Table 3: Bivariate Analysis of Socio-Demographic Determinants

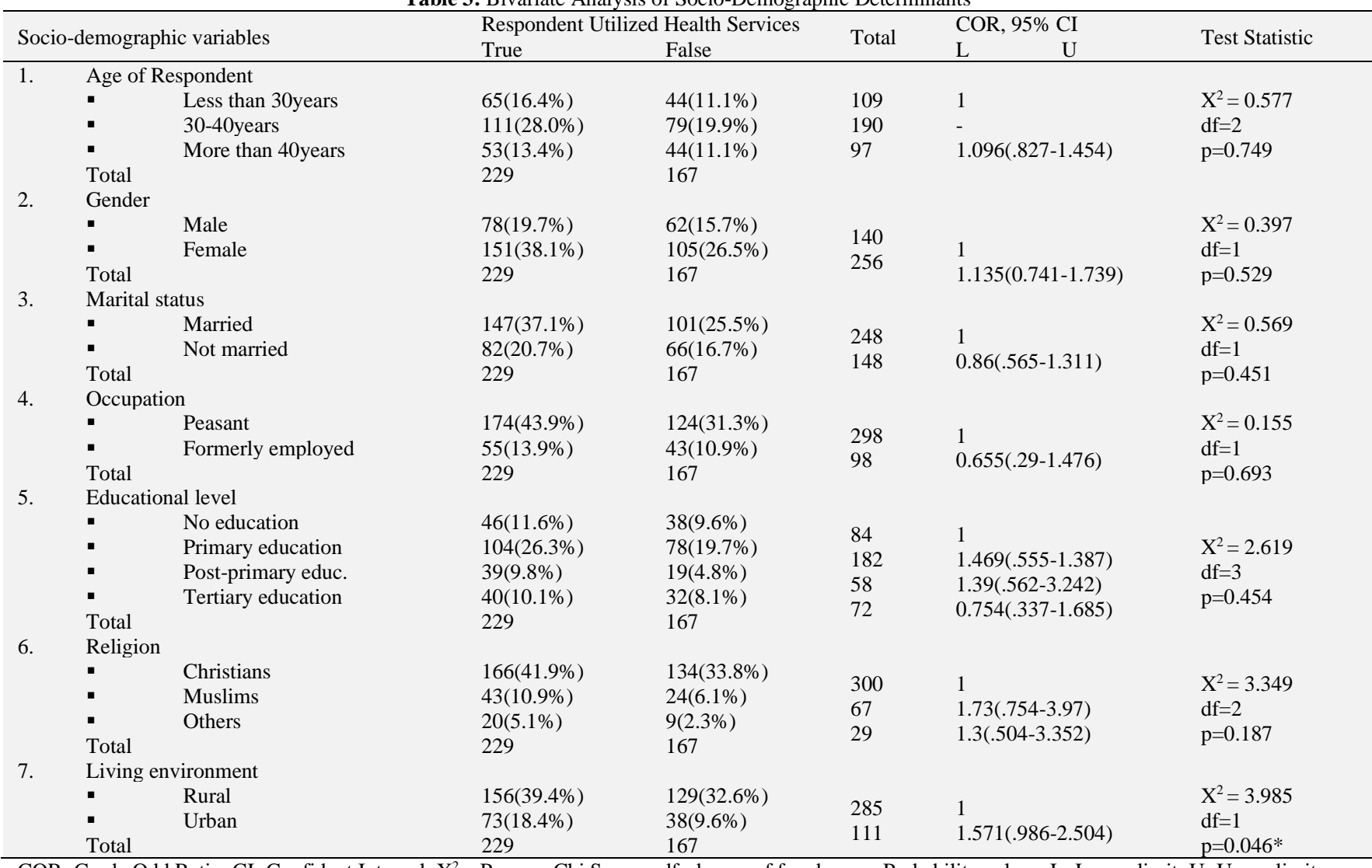

COR=Crude Odd Ratio, CI=Confident Interval, $\mathrm{X}^{2}=$ Pearson Chi Square, $\mathrm{df}=$ degree of freedom, $\mathrm{p}=$ Probability values, $\mathrm{L}=\mathrm{L}$ -

The living environment of respondents was the only socio-demographic variable found significantly determine health service utilization in Dokolo Health Centre IV ( $\mathrm{p}$-value $=0.046$ ). Living in urban area was 1.6 times more likely to be a determinant of health service utilization than living in rural setting [COR=1.571, 95\% CI (0.986-2.504)].

From table 3 above, most of the respondents who utilized health services were aged 30-40years, accounting for 111(28.0\%) of all respondents. Age was not found to be a determinant of health service utilization. Even though gender was not a statistically significant determinant of health service utilization $(\mathrm{p}=0.529)$, most of the females $151(38.1 \%)$ utilized health services. The study found that being a female was 1.14 times more likely to utilize health services (COR=1.135, 95\% CI (0.741-1.739)).

Most of the married respondents, 147(37.1\%), utilized health services, and thus being unmarried was 0.9 times less likely to be associated with utilization of health services (COR=0.86, 95\% CI (0.565-1.311)). Similarly, majority of the respondents who were peasants, 174(43.9\%), utilized health services from the facility as opposed to their formally employed counterparts. Thus, being formally employed was 0.7 times less likely to utilize health services from the facility $(\mathrm{COR}=0.655,95 \% \mathrm{CI}(0.29-1.476))$. 
Most of the respondents with primary education [104(26.3\%)], utilized health services followed by those with no education [46(11.6\%)]. However, primary education was 1.5 times more likely to be associated with utilization of health services [COR $=1.469,95 \%$ CI $(0.555-$ 1.387)] followed by post-primary education which was 1.4 times more likely to utilize health services [COR $=1.39$, $95 \%$ CI $(0.562$ 3.242)]. Whereas most Christians 166(41.9\%), utilized health services, being a Muslim was 1.7 times more likely to make one utilize health services from Dokolo HC IV [COR $=1.73,95 \%$ CI (.754-3.97)]. Similarly, being in other religious denomination was 1.3 times more likely for a respondent to utilize health services [COR=1.3, 95\% CI (0.504-3.352)].There was no significant finding at multivariate analysis.

\subsection{Enabling determinants of health service utilization among users}

A cross-tabulation and bivariate analysis was done to determine the enabling determinants of health services utilization. The results are shown in table 4 below.

Table 4: Bivariate Analysis of Enabling Determinants

\begin{tabular}{|c|c|c|c|c|c|c|}
\hline \multirow{2}{*}{\multicolumn{2}{|c|}{ Enabling variables }} & \multicolumn{2}{|c|}{$\begin{array}{l}\text { Respondent Utilized Health } \\
\text { Services }\end{array}$} & \multirow[t]{2}{*}{ Total } & COR, $95 \% \mathrm{CI}$ & \multirow[t]{2}{*}{ Test Statistic } \\
\hline & & True & False & & $\mathrm{L} \quad \mathrm{U}$ & \\
\hline 1. & $\begin{array}{l}\text { Respondent satisfied with services } \\
\text { - } \quad \text { Yes } \\
\text { - } \quad \text { No } \\
\text { Total }\end{array}$ & $\begin{array}{l}105(26.5 \%) \\
124(31.3 \%) \\
229\end{array}$ & $\begin{array}{l}1(0.3 \%) \\
166(41.9 \%) \\
167\end{array}$ & $\begin{array}{l}106 \\
290\end{array}$ & $0.000(0.000-0.001)$ & $\begin{array}{l}X^{2}=100.886 \\
d f=1 \\
p=0.000 * *\end{array}$ \\
\hline 2. & 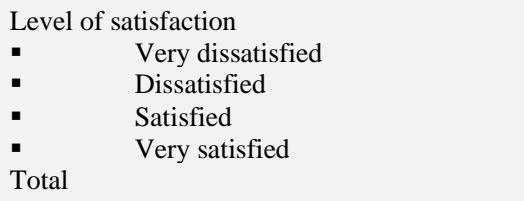 & $\begin{array}{l}42(10.6 \%) \\
82(20.7 \%) \\
82(20.7) \\
23(5.8 \%) \\
229\end{array}$ & $\begin{array}{l}44(11.1 \%) \\
122(30.8 \%) \\
1(0.3 \%) \\
0(0.0 \%) \\
167\end{array}$ & $\begin{array}{l}86 \\
204 \\
83 \\
23\end{array}$ & $\begin{array}{l}0.717(0.429-1.198) \\
16(.000-0.001)\end{array}$ & $\begin{array}{l}X^{2}=102.749 \\
d f=3 \\
p=0.000 * *\end{array}$ \\
\hline 3. & $\begin{array}{l}\text { House-hold monthly income } \\
\text { Less than UGX100.000/= } \\
\text { UGX100.000/= to UGX300.000/= } \\
\text { More than UGX300.000/= } \\
\text { Total }\end{array}$ & $\begin{array}{l}121(30.6 \%) \\
41(10.4 \%) \\
67(16.9 \%) \\
229\end{array}$ & $\begin{array}{l}91(23.0 \%) \\
31(7.8 \%) \\
45(11.4 \%) \\
167\end{array}$ & $\begin{array}{l}212 \\
72 \\
112\end{array}$ & - & $\begin{array}{l}X^{2}=0.255 \\
d f=2 \\
p=0.88\end{array}$ \\
\hline 4. & $\begin{array}{l}\text { Ability to pay } \\
\text { - } \\
\text { - } \\
\text { Total }\end{array}$ & $\begin{array}{l}63(15.9 \%) \\
166(41.9 \%) \\
229\end{array}$ & $\begin{array}{l}39(9.8 \%) \\
128(32.3 \%) \\
167\end{array}$ & $\begin{array}{l}102 \\
294\end{array}$ & $1.054(0.59-1.882)$ & $\begin{array}{l}X^{2}=0.873 \\
d f=1 \\
p=0.35\end{array}$ \\
\hline 5. & $\begin{array}{l}\text { Distance to health facility } \\
\text { - } \quad 1-3 \mathrm{Km} \\
\text { - } \quad \text { More than } 3 \mathrm{Km} \\
\text { Total }\end{array}$ & $\begin{array}{l}73(18.4 \%) \\
36(9.1 \%) \\
120(30.3 \%) \\
229\end{array}$ & $\begin{array}{l}37(9.3 \%) \\
30(7.6 \%) \\
100(25.3 \%) \\
167\end{array}$ & $\begin{array}{l}110 \\
66 \\
220\end{array}$ & $\begin{array}{l}0.788(0.442-1.403) \\
1.159(0.602-2.233)\end{array}$ & $\begin{array}{l}X^{2}=4.550 \\
d f=2 \\
p=0.033^{*}\end{array}$ \\
\hline 6. & $\begin{array}{l}\text { Influence on Decision to Use Health Facility } \\
\text { - } \\
\text { Weak influence } \\
\text { Moderate influence } \\
\text { Total } \\
\end{array}$ & $\begin{array}{l}99(25.0 \%) \\
58(14.6 \%) \\
72(18.2 \%) \\
229\end{array}$ & $\begin{array}{l}78(19.7 \%) \\
40(10.1 \%) \\
49(12.4 \%) \\
167\end{array}$ & $\begin{array}{l}177 \\
98 \\
121\end{array}$ & $\begin{array}{l}1.392(0.8-2.423) \\
0.938(0.506-1.74)\end{array}$ & $\begin{array}{l}X^{2}=0.474 \\
d f=2 \\
p=0.789\end{array}$ \\
\hline
\end{tabular}

COR=Crude Odd Ratio, CI=Confident Interval, $\mathrm{X}^{2}=$ Pearson Chi Square, $\mathrm{df}=$ degree of freedom, $\mathrm{p}=$ Probability values, $\mathrm{L}=\mathrm{Lower}$ limit, $\mathrm{U}=\mathrm{Upper}$ limit.

As seen in table 4 above, satisfaction with services $(\mathrm{p}=0.000)$, level of satisfaction $(\mathrm{p}=0.000)$ and distance to health facility $(\mathrm{p}=0.033)$ were the enabling determinants found to be associated with utilization of health services in Dokolo HC IV. Most of the respondents $(105(26.5 \%))$ who were satisfied with services utilized the health services in the health institution while only one (0.3\%) self-reported not to have utilized health services from Dokolo HC IV.

In terms of levels of satisfaction, being very satisfied was 16 times more likely for one to utilize health services from Dokolo HC IV $[\mathrm{COR}=16,95 \% \mathrm{CI}(0.000-0.001)]$. Similarly, respondents whose distance to health facility was more than 3 kilometers were 1.2 times more likely to utilize health services from the facility [COR $=1.159,95 \%$ CI $(0.602-2.233)]$ compared to those with shorter distance to health facility.

\subsection{Opinions of health service users on utilization of health services}

To determine the opinions of health service users on utilization of health services in Dokolo Health Centre IV, three focus group discussions were held; two in the community and one in the health facility. The focus group discussions were classified as ' $\mathrm{A}$ ', ' $\mathrm{B}$ ' and ' $\mathrm{C}$ ' and the opinions were sub-categorized into the following themes as under;

\section{Theme 1: Perceived Quality of Care}

Respondents were asked about what they thought about the quality of care in the health institution. Most of the respondents rated the quality of care as poor.

"[...] I have been getting medical care from here for long. But up to now I'm still sick. No improvement. So, to me the quality is really low. May be [...]" - Respondent 1 in FGD 'A'

"These health workers, the quality of their care is not to the standard. They need to improve [...]" - Respondent

7 in FGD ' $C$ ' 
"[...] For me, I think they are too few to offer quality services ... [...]" - Respondent 4 in FGD 'A '

"[...] don't blame them. Services in public or government institutions are always like that. Only the very poor will keep going there" - Respondent 2 in $F G D$ ' $B$ '

Therefore, generally most respondents rate the quality of care as poor. With this, more is still wanting in order to improve quality of care in the facility.

\title{
Theme 2: Services Meeting Needs of Users
}

In terms of services meeting needs of users, there were two sub-themes;

\section{Sub-theme 2(a): Availability of Required Services}

Among the respondents who ever got services from the public health facility, many of them reported that there were only basic services. In fact the services were not comprehensive. The respondent reported as below;

"[...] Yes, some services are there. But there are many services which are not there, for example, the health workers after reviewing you say that you go and buy medicine from clinics outside. This is a clear sign that drugs are not enough." - Respondent 6 in $F G D$ ' $B$ '

“...I was told to go and do investigations from outside the hospital..." - Respondent 9 in FGD 'C'

"[...] I didn't get all the services I needed. They told me that the doctor was busy. And I had nothing to do." Respondent 8 in FGD 'A'

Sub-theme 2(b): Services met Expectations of Users

Whereas, some respondents had their expectations met, services didn't meet expectation of many users as well.

"[...] Me I went to the hospital because I was feeling hot. They did everything and wrote for me the medicine. I got my medicine and went back home. But this is really rear as ..." - Respondent 5 in FGD 'B'.

Respondent 5 in focus group discussion 'B' above, was among those respondents whose expectations were met.

"[...] Because I was very sick, I had to keep going back for up to three days before I could get help. Even then, I had to buy medicine from outside ..." - Respondent 1 in FGD ' $C$ '

Respondent 1 in focus group discussion ' $\mathrm{C}$ ' above was among those respondents whose expectations were not met.

Theme 3: Waiting Time

Waiting time in the health facility is far longer than expected. All the respondents in all the focus groups report very long waiting time in the health facility.

"[...] In fact, if you are very sick then you better go to a private clinic. Otherwise, you will just die in the queue waiting to be seen" - Respondent 7 in FGD 'A'

\section{“[...] I too waiting for so long [...]"- Another respondent who interjected}

A lot more still need to be done to improve on the waiting time of users of the facility.

\section{Theme 4: Healthcare Providers' Attitudes}

There were mixed reactions about attitudes or reception of healthcare providers towards users of the facility. Even so, majority of the healthcare providers appeared to be hostile to the users. The respondents had these to say;

"[...] most of them talk in an arrogant manner to patients and yet we go to them because of sickness. It is even worse when they are tired. You care really get embarrassed." - Respondent 4 in FGD 'B'

The other respondents gave similar picture that portrayed negative attitudes towards helping users and their services user friendly. They reported as;

\author{
"[...] They need to be taught good customer care ...." - Respondent 3 in FGD 'C' \\ "[...] I felt so bad on that day ..." - Respondent 2 in FGD 'A'
}

\section{Discussion}

The findings showed thatonly $26.8 \%$ of the users were at least satisfied with services provided in the health facility. This was far below findings in other studies as compared to $90.6 \%$ who rated the services to be at least good; $95.9 \%, 94.3 \%$ and $95.8 \%$ of the respondents were, satisfied with the childhood immunisation, antenatal care and childbirth services in that respective order (Uzochukwu, Onwujekwe, \& Akpala, 2004). In India, level of satisfaction was determined by waiting time $(\mathrm{p}<0.01)$, paying status $(\mathrm{p}<0.01)$ and availability of drugs within the facility $(\mathrm{p}<0.01)$ (Birna, 2006).

Living environment of the respondents was the only socio-demographic variable found to significantly determine health service utilization in Dokolo Health Centre IV (p-value $=0.046$ ). Living in urban area was 1.6 times more likely to be a determinant of health service utilization than living in rural setting [COR=1.571, 95\% CI (0.986-2.504)].In South Africa, $75 \%$ of participants reported reduced quality 
of public health services as a major reason not to visit them. Higher odds of reported health-care utilization were associated with being female $(\mathrm{OR}=2.18,95 \%$ CI: 1.88-2.53; p < 0.001)(Abaerei, Ncayiyana, \& Levin, 2017). In another study, age and marital status were significantly associated with health services utilization (Zhang, Chen, \& Zhang, 2019).

Satisfaction with services $(\mathrm{p}=0.000)$ and distance to health facility $(\mathrm{p}=0.033)$ were the enabling determinants found to be associated with utilization of health services in Dokolo HC IV. In South Africa, higher odds of reported health-care utilization were associated having medical insurance $(\mathrm{OR}=5.41,95 \% \mathrm{CI}$ : 4.06-7.23; p < 0.001). Lower odds of seeking health-care were associated with being an immigrant $(\mathrm{OR}=0.61$, 95\% CI: $0.53-0.70$; $\mathrm{p}<0.001$ ) (Abaerei, Ncayiyana \& Levin, 2017).Thus, findings from this study are in less agreement with other scholars due to a difference in variables used.

In this study, the opinions pointed toward reduced utilization because of a number of negative experiences. Most of the respondents rated the quality of care as poor. Many reported that services provided were only basic and not comprehensively meeting their health needs. This finding is similar to those got elsewhere. For example, in South Africa75\% of participants reported reduced quality of public health services as a major reason not to visit them(Abaerei, Ncayiyana, \& Levin, 2017).

\section{Conclusion}

Health service utilization, especially in public health facility remains a big problem. Growing demands for healthcare, rising costs, constrained resources and evidence of variation in clinical practice have affected health service utilization by many patients. The opinions of users about the health care services and the degree of their satisfaction may indicate the efficiency of the services. This prompts another area worth studying.

\section{Acknowledgement}

The authors acknowledge the support from Faculty of Health Sciences (FHS) of Uganda Martyrs University for being pro-active in research. Appreciations go to all our study participants.

\section{Declaration}

The authors declare no conflict of interest.

\section{References}

[1] Abaerei, A. A., Ncayiyana, J., \& Levin, J. (2017). Health-care utilization and associated factors in Gauteng province, South Africa. Global Health Action, 10 (1).https://doi.org/10.1080/16549716.2017.1305765.

[2] Birna, A. (2006). The quality of hospital services in eastern Ethiopia: Patient's Perspective. Ethiopian Jounal of Health Develpment, 20 (3), 199200.

[3] Brzoska, P., Erdsiek, F., \& Waury, D. (2017). Enabling and predisposing factors for the utilization of preventive dental health care in migrants and non-migrants in Germany. Frontiers in Public Health, 5 (201).https://doi.org/10.3389/fpubh.2017.00201.

[4] Donabedian, A. (1973). Donab Aspects of Medical Care Administration: Specifying Requirements for Health Care Cambridge. MA: Harvard University Press.

[5] Folland, S., Goodman, A. C., \& Stano, M. L. (2006). The Economics of Health and Health Care (5th ed.). Upper Saddle River, NJ: Prentice Hall.

[6] Guinness, L., Repon, P., \& Augu, M. (2018). Determinants of health care utilisation: the case of Timor-Leste. International Health, 10(6), 412420.https://doi.org/10.1093/inthealth/ihy044.

[7] Gutierrez, R., Teshome, S., \& Neilson, M. (2018). Uganda's Health Care Quality Improvement Journey. TechnicalReport

[8] Haggerty, J. L., Pineault, R., Beaulieu, M., Brunelle, Y., Gauthier, J., Goulet, F., et al. (2008). Practice Features Associated With Patient-Reported Accessibility, Continuity, and Coordination of Primary Health Care. Annals of Family Medicine, 6 (2), 116-23.https://doi.org/10.1370/afm.802.

[9] Israel, D. G. (1992). Determining Sample Size [Pdf $\quad$ on line]. Retrieved from https://www.tarleton.edu/academicassessment/documents/Samplesize.pdf.

[10] Lancet. (2014). Universal health coverage post-2015: putting people first.

[11] Musoke, D., \& Boynton, P. (2018). Health seeking behaviour and challenges in utilising health facilities in Wakiso district, Uganda.

[12] Mwesigwa, L. C., \& Okumu, A. B. (2020). Mapping the geographic availability of public dental services in Uganda relative to ruralization and poverty of the population.https://doi.org/10.25259/JGOH_66_2019.

[13] Qais, A., Carl, S., Patrick, M. K., Valerie, S., Didem, D., Kelly, B., et al. (2017). Determinants of Health Care Services Utilization among First Generation Afghan Migrants in Istanbul. International Journal of Environmental Research and Public Health, 14 (2), 201.https://doi.org/10.3390/ijerph14020201.

[14] Terfa, B. Y., \& Germossa, N. G. (2019). Determinants of Health Care Utilization among the Elderly Popu-lation in Jimma Town, Oromia Region, Southwest Ethiopia.

[15] Uzochukwu, B. S., Onwujekwe, O. E., \& Akpala, C. O. (2004). Community satisfaction with the quality of maternal and child health services in Southeast Nigeria. East African Medical Journal, 81 (6).https://doi.org/10.4314/eamj.v81i6.9178.

[16] Zhang, S., Chen, Q., \& Zhang, B. (2019). Understanding Healthcare Utilization In China Through The Andersen Behavioral Model: Review Of Evidence From The China Health And Nutrition Survey.https://doi.org/10.2147/RMHP.S218661.

\section{Appendix I: QUESTIONAIRES}

\section{SECTION A - Utilization of Health Services \& Satisfaction}

Tick the appropriate box for each response

1) In the past 6months, did you or any member of your household get any health service (s) from Dokolo Health Centre IV?

I got health service from the facility; True False

2) If it is true, were you satisfied with the service (s) got? Yes 
3) Again, if it true that you got health service (s) from the facility, rate you level of satisfaction in a Likert scale of 1-4 below;

1=Very dissatisfied, $2=$ Dissatisfied, $3=$ =Satisfied, $4=$ =ery Satisfied

\begin{tabular}{cccc}
\hline $1=$ Very dissatisfied & 2=Dissatisfied & $3=$ Satisfied & 4=Very satisfied \\
$\square$ & $\square$ & $\square$ & $\square$ \\
\hline
\end{tabular}

SECTION B - Socio-demographic \& Enabling Determinants of HSU

Socio-demographic Variables of each respondent

01

Age of respondent

Less than 30years

30 - 40years

More than 40years

02

Gender of respondent

Male

Female

03

Marital status

Married

Not married

04

Occupation of respondent

Peasant

Formally employe

05

Educational level of respondent

No education

Primary education

Post-primary education

06

Tertiary education

Religion

Christian

Muslim

Others

07

Living Environment

Rural

Urban

Enabling Variables of each respondent

01

Regular Monthly House-hold income (Ugandan Shillings)

Less than UGX100,000/= $\square$

UGX $100,000 /=$ to UGX $300,000 /=$

More than UGX 300,000/=

02

Ability to pay: Are you able to pay for health services, in case you are asked to?

Yes

No

03

Distance to Health Facility

Less than $1 \mathrm{Km}$

$1-3 \mathrm{Km} \square$

More than $3 \mathrm{Km}$

04

Influence on decision to use Health Facility: Rate your influence in this $\mathrm{HH}$ on decision to use the HF Weak influence $\square$

Moderate influence

Strong influence

THE END

\section{Appendix II: FOCUS GROUP DISCUSSION GUIDE}

If you ever got health service (s) from Dokolo HC IV, please share with me your opinions on HSU in the facility

Qn1. What was the quality of care? [Self-evaluating perceived quality of care]

Qn2. Are the services you need available in the facility, each time you need it/them? [Probing availability of services]

Qn3. What is the average waiting time to get a service? Does it affect your utilization of health services? Explain. [Probing waiting time experiences] 
Qn4. Does Dokolo HC IV meet your needs? Explain [probing meeting needs of users]

Qn5. What do you say about the health care providers' attitudes towards your utilization of health services? [Probing HC providers' attitudes]

\section{THE END}

